\title{
O CORPO E AADOÇÃO DE PRÁTICAS SUSTENTÁVEIS: ESTUDO DE CASO EM UMA ECOVILA
} ELCUERPOYLAADOPCIÓNDEPRÁCTICASSUSTENTABLES:ESTUDIODE
CASO EN UNA ECOALDEA
THE BODY AND THE ADOPTION OF SUSTAINABLE PRACTICES: A CASE
STUDY IN AN ECOVILLAGE

http://dx.doi.org/10.1590/1807-0310/2018v30164236

Rebeca Roysen

Universidade de Brasília, Brasília/DF, Brasil

\section{RESUMO}

Este artigo busca investigar o papel do corpo na adoção de práticas sociais sustentáveis. Apoiando-se nas Teorias das Práticas Sociais, aponta para o papel da rotinização na manutenção de estilos de vida insustentáveis. Com base em um estudo de caso realizado em uma ecovila brasileira, demonstra que a existência de valores ambientais não leva as pessoas a automaticamente modificarem os seus comportamentos. A mudança das práticas cotidianas exige a modificação de hábitos e automatismos incorporados pela socialização na sociedade de consumo. A incorporação intencional de novas práticas é um processo que demanda tempo e um trabalho de percepção consciente, sendo facilitada quando existe um esforço explícito e articulado de mudança, compartilhado por um grupo social.

Palavras-chave: comportamento ambiental; teoria das práticas sociais; ambientalismo; sustentabilidade; psicologia ambiental.

\section{RESUMEN}

Este artículo pretende investigar el papel del cuerpo en la adopción de prácticas sociales sostenibles. Basándose en las Teorías de las Prácticas Sociales, señala el papel de la rutinización en el mantenimiento de estilos de vida insustentables. Basado en un estudio de caso realizado en una ecoaldea brasilera, demuestra que la existencia de valores ambientales no conduce a las personas a modificar automáticamente sus comportamientos. El cambio de las prácticas diarias exige la modificación de hábitos y automatismos incorporados por la socialización en la sociedad de consumo. La incorporación intencional de nuevas prácticas es un proceso que requiere tiempo y un trabajo de percepción consciente, facilitada cuando hay un esfuerzo explícito y articulado para el cambio, compartido por un grupo social.

Palabras clave: comportamiento ambiental; teoría de las prácticas sociales; ambientalismo; sustentabilidad; psicología ambiental.

\begin{abstract}
This article investigates the role of the body in the adoption of sustainable social practices. Based on Social Practice Theories, it indicates the role of routinization in the maintenance of unsustainable lifestyles. Grounded in a case study carried out in a Brazilian ecovillage, it shows that the existence of environmental values does not automatically lead people to change their behaviors. The transformation of daily practices demands a change in habits and automatisms embodied through one's socialization in the consumer society. The intentional embodiment of new practices is a process that demands time and a work of conscious perception, facilitated when there is an explicit and articulated change effort, shared by a social group.
\end{abstract}

Keywords: environmental behavior; social practice theory; environmentalism; sustainability; environmental psychology. 


\section{Introdução}

Diversos estudos sobre a crise ecológica têm indicado que mudanças políticas não serão suficientes para deter a atual crise se não se transformarem, também, os estilos de vida da sociedade de consumo (Raskin et al., 2002; Raskin, Electris, \& Rosen, 2010; Steffen et al., 2005). Estimativas sugerem que aproximadamente $40 \%$ das emissões de carbono estão relacionadas a práticas de uso doméstico de energia e práticas de mobilidade e transporte (Fudge, Peters, Hoffman, \& Wehrmeyer, 2013). Dessa forma, fica cada vez mais evidente que a mudança das práticas cotidianas dos indivíduos deve ser parte integrante das políticas de redução das emissões de gases de efeito estufa (Abrahamse \& De Groot, 2013; Fudge et al., 2013; Shove \& Walker, 2010; Spaargaren, 2011).

O fato de que a atual crise ecológica exige mudanças não apenas políticas e econômicas, mas também culturais, tem levado muitos pesquisadores a investigar temas como: percepções sobre o ambiente (Gonçalves \& Gomes, 2014; Peterlin, Kross, \& Kontic, 2008; Ratter, Philipp, \& Von Storch, 2012), níveis de preocupação ambiental (Alibeli \& White, 2011; Dunlap, 1994; Feinberg \& Willer, 2013) e influência dos valores e crenças na adoção de comportamentos mais sustentáveis (Best \& Mayerl, 2013; De Groot \& Steg, 2010; Harder et al., 2014). No entanto, muitos pesquisadores têm percebido que valores ecológicos, consciência ambiental e percepções favoráveis não se traduzem diretamente em comportamento ambientalmente responsável (Ester, Vinken, \& Simões, 2004; Rodríguez-Barreiro et al., 2013; Tanner, 1999). Isso é chamado de lacuna valor-ação (valueaction gap). "Paradoxalmente, o nível crescente de preocupação pública e de disposição para apoiar ações ambientais está crescendo simultaneamente com os níveis de consumo de energia e de uso de recursos escassos" (Ester et al., 2004, p. 46)1.

Por que a preocupação com o meio ambiente não leva as pessoas a modificarem os seus hábitos cotidianos? Alguns autores atribuem esse fato a constrangimentos externos, tais como políticas públicas e infraestrutura, ou limitações de tempo e dinheiro (Kaiser, Wolfing, \& Fuhrer, 1999; Tanner, 1999). Segundo as Teorias das Práticas Sociais (TPS), essa lacuna entre consciência ambiental, de um lado, e comportamento pró-ambiental, de outro, pode ser explicada pelo fato de que as práticas cotidianas não surgem unicamente de uma escolha individual e racional, mas estão ligadas (a) às infraestruturas de abastecimento, aos objetos e tecnologias disponíveis; (b) aos significados associados às práticas, aos valores e normas sociais; (c) às competências e hábitos incorporados - enfim, a uma série de elementos que constituem as práticas e que não podem ser localizados no indivíduo isolado (Shove \& Walker, 2010; Shove, Watson, \& Spurling, 2015; Spaargaren, 2011).

A TPS, ao buscar superar o individualismo da perspectiva comportamentalista, explicita os elos entre os comportamentos individuais, os sistemas tecnológicos e as normas culturais de uma sociedade. Ela traz, portanto, uma nova perspectiva para se pensar a transformação das práticas na direção da sustentabilidade. Nessa perspectiva, o comportamento das pessoas não é sempre fruto de uma intenção racional, mas, muitas vezes, parte de um fluxo contínuo e habitual de ação. A natureza da estrutura social é a rotinização (Giddens, 2007; Reckwitz, 2002; Shove, Pantzar, \& Watson, 2012).

Uma das definições mais utilizadas de práticas sociais é a de Reckwitz (2002), que as define como "um tipo rotinizado de comportamento que consiste de diversos elementos interconectados: formas de atividades corporais, formas de atividades mentais, 'coisas' e seus usos, um conhecimento contextual na forma de entendimento, know-how, estados emocionais e conhecimento motivacional" (p. 249). As formas como as pessoas lidam com os resíduos, utilizam água e energia, consomem e se locomovem são práticas sociais inscritas em seus corpos, possibilitadas pela infraestrutura e objetos disponíveis, e ligadas a formas de entender, sentir e querer. Nessa perspectiva, portanto, um elemento importante na mudança cultural, além da transformação das percepções, valores e crenças e da criação de novas estruturas e tecnologias, é a mudança corporal: a incorporação de novos hábitos, condicionamentos e formas de conhecimento tácito (Bourdieu, 2012; Lizardo, 2009; Reckwitz, 2002).

Para entender melhor esse fenômeno, realizei um estudo de caso com um grupo de ativistas que fazem parte de uma ecovila. Ecovilas são comunidades intencionais sustentáveis, isto é, são grupos de pessoas que se unem para criar um estilo de vida de baixo impacto ambiental e relações interpessoais mais cooperativas e solidárias (Boyer, 2016; Capello, 2013; Ergas, 2010). Os membros da ecovila estudada nesta pesquisa demonstram alto nível de conhecimento e preocupação ambiental e buscam colocar em prática os seus valores, assumindo deliberadamente uma mudança nos seus estilos de vida.

O objetivo deste estudo foi o de investigar os aspectos culturais dessa ecovila, procurando explorar as possibilidades e dificuldades encontradas nesse processo de mudança cultural. Este artigo está 
dividido em cinco partes. Após esta Introdução, reviso alguns estudos que exploram o elemento corporal na mudança das práticas (seção 2). Em seguida, descrevo a metodologia de pesquisa (seção 3). Na quarta seção, apresento a ecovila estudada e exploro as conquistas e dificuldades encontradas no processo de mudança cultural proposta pelos seus membros. Na quinta seção, discuto os dados levantados e encaminho as conclusões do estudo.

\section{O corpo e a mudança cultural}

Diversos estudos têm sugerido que práticas sociais insustentáveis persistem não porque as pessoas não possuem valores ou preocupações com o meio ambiente, mas devido à tendência do corpo em repetir formas de ação incorporadas durante a vida (Bourdieu, 1995; Lizardo, 2009; Shove et al., 2012; Swidler, 1986). Os indivíduos são socializados em ambientes interpessoais e ecológicos específicos e, nessa socialização, as informações que guiam a ação humana são guardadas na forma de representações motoras esquemáticas (Bourdieu, 1995; Lizardo, 2009; Maller \& Strengers, 2015). Dessa forma, a cultura não é compartilhada somente como valores e histórias possíveis de serem verbalizadas, mas, principalmente, como saberes-fazeres. "Ser parte de um coletivo implica incorporar, em um sentido muito literal, conhecimentos e habilidades incorporados que são codificados em uma memória procedimental e não declarativa" (Lizardo, 2009, p. 721).

Para Bergson (2010), esse automatismo é uma espécie de memória armazenada no corpo (distinta, portanto, da memória-lembrança) e que é adquirida pela repetição de um mesmo esforço. Toda percepção provoca em nós movimentos motores pelo menos nascentes. "Esses movimentos, ao se repetirem, criam um mecanismo, adquirem a condição de hábito, e determinam em nós atitudes que acompanham automaticamente nossa percepção das coisas" (p. 91). $\mathrm{E}$, assim, estar adaptado ao ambiente em que vivemos é esboçar, a cada percepção, movimentos habituais. À medida que a impressão se repete, a conexão se consolida, formando um mecanismo motor que tende a responder à nossa percepção das coisas com os mesmos movimentos, na mesma sequência e no mesmo espaço de tempo. Essa memória "já não nos representa o nosso passado, ela o encena" (Bergson, 2010 , p. 89). Consequentemente, para efetuar uma mudança cultural é necessário romper com esses automatismos e criar novas conexões, novas respostas para as situações dadas, em uma mudança que é, portanto, também corporal.
Maller e Strengers (2015) partem dos estudos da biofísica sobre "memória muscular" e chegam a conclusões muito similares à de Bergson. Segundo elas, a repetição das práticas deixa marcas ou traços nos padrões mentais e corporais dos praticantes, incorporando-se em seus "corpos-mentes" e formando o que as autoras chamam de "memória da prática". Competências e habilidades se tornam, assim, profundamente consolidadas nos músculos e não precisam de reflexão consciente para ser executadas. Quanto mais intenso e duradouro o treinamento de uma prática por um indivíduo, mais forte a memória da prática.

Dessa forma, as práticas das gerações passadas influenciam as práticas contemporâneas tanto por meio da acumulação de materiais, tecnologias e recursos como pela criação de disposições incorporadas nos indivíduos e que geram definições sobre o que é possível ou impossível, o que é comum ou escandaloso, tendendo a reproduzir as práticas nas quais foram formados. A essas disposições incorporadas, Bourdieu (1995) chama de habitus. O habitus refere-se a necessidades sociais que se convertem em esquemas motores e automatismos corporais, nos quais os condicionamentos associados a uma classe particular de condições de existência produzem princípios (naturalizados, não conscientes) geradores e organizadores de práticas e representações. O habitus...

garante a presença ativa das experiências passadas que, depositadas em cada organismo sob a forma de esquemas de percepção, de pensamento e de ação, tendem, de forma mais segura que todas as regras formais e que todas as normas explícitas, a garantir a conformidade das práticas e sua constância ao longo do tempo. (Bourdieu, 2009, p. 90)

Assim, cada ordem estabelecida cria, de um lado, estruturas objetivas e, de outro, um corpo socialmente informado adequado a essas estruturas, com seus gostos e desgostos, suas compulsões e repulsões, seu senso de necessidade e de realidade, naturalizando a arbitrariedade dessa ordem. Dessa forma, a mudança das práticas cotidianas na direção da sustentabilidade exige não só a construção de novas estruturas objetivas, mas, também, que os indivíduos modifiquem hábitos e automatismos criados pela repetição de práticas insustentáveis normatizadas pela sociedade de consumo.

Lewin (1983), ao analisar o processo de mudança cultural - ao qual ele chama de reeducação -, percebeu a importância dessa questão. Segundo ele, o processo reeducativo afeta o indivíduo de três maneiras: mudando a estrutura cognitiva (a maneira de 
ver o mundo, fatos, conceitos, crenças e expectativas); suas valências e valores (atrações e aversões, reações às fontes de aprovação e desaprovação) e sua ação motora (o grau de controle do indivíduo sobre seus movimentos físicos e sociais). No entanto, Lewin segue sua explanação abrangendo apenas os dois primeiros aspectos, sem desenvolver o terceiro aspecto, o da mudança corporal.

Um físico que estudou profundamente o movimento e a mudança corporal foi Feldenkrais (1977, 1988). Segundo ele, a melhor forma de modificar hábitos não é pela força, mas pela percepção consciente: dirigindo nossa atenção às ações que fazemos habitualmente, trazendo-as à consciência. Essa é uma possibilidade intrínseca aos seres humanos, pela nossa capacidade de "atrasar" a execução de uma ação. Segundo ele, esse atraso entre o processo de pensamento e sua tradução em ação nos permite examinar o que está acontecendo dentro de nós e, assim, quebrar o automatismo.

Este fato é ilustrado pela velha história da centopeia que não sabia mais andar, depois que lhe perguntaram em que ordem ela movia suas múltiplas pernas. É bastante frequente que quando perguntamos a uma pessoa o que ela está fazendo, que ela se torne confusa e incapaz de continuar... Sem consciência, nós realizamos o que os velhos sistemas cerebrais fazem à sua própria maneira. (Feldenkrais, 1977, p. 68)

No entanto, para Feldenkrais, essa percepção exige um esforço mental consciente até que a nova forma de ação deixe de ser percebida como anormal e se torne um novo hábito. Em um estudo realizado no Reino Unido, por exemplo, Thomas e Sharp (2013) também identificaram que a inserção da reciclagem no cotidiano dos indivíduos exige "forte motivação interna", até que se torne um novo hábito.

Os teóricos das práticas sociais também apontam para a possibilidade de uma mudança consciente das práticas (Giddens, 2007; Shove et al., 2012). Segundo eles, os indivíduos possuem um entendimento reflexivo e são capazes de monitorar e avaliar as suas práticas. Nesses casos, o monitoramento das práticas dá aos praticantes um feedback sobre os resultados da ação passada, alimentando ações futuras.

\section{Metodologia}

Este artigo está baseado em uma pesquisa de campo realizada em uma ecovila localizada no interior do Estado de São Paulo, entre os meses de março e novembro de 2011. Nesse período, realizei visitas semanais à comunidade, procurando acompanhar as reuniões, eventos e a vida cotidiana de seus membros. O levantamento de dados se deu por meio de dois instrumentos:

1. Diário de campo, redigido a partir das observações sobre as práticas cotidianas dos membros da ecovila, suas relações interpessoais e com a natureza, seus projetos e conflitos;

2. Entrevistas qualitativas semiestruturadas realizadas com os membros mais efetivos, sendo sete moradores e dois membros que não moram na ecovila, mas assumem papéis ativos na organização comunitária. Dos entrevistados, cinco são mulheres e quatro homens, com idades entre 49 e 70 anos. $\mathrm{O}$ roteiro de entrevista foi formulado e reformatado após a realização de entrevistas-piloto em duas outras comunidades. As entrevistas "oficiais" foram gravadas mediante consentimento dos entrevistados e, depois de transcritas, foram devolvidas aos seus autores para aprovação, cuidando para que suas vozes fossem respeitadas.

Os nomes da comunidade e de seus membros foram omitidos ou trocados para preservar as suas identidades e permitir maior liberdade de expressão pelos entrevistados. Após a pesquisa de campo, todas as entrevistas foram transcritas, impressas e encadernadas, juntamente com o diário de campo. Esse material passou, então, por uma codificação qualitativa (Sampieri, Collado, \& Lucio, 2013). Os trechos retirados das entrevistas estão destacados em itálico.

Importante ressaltar que a observação em campo incluiu a auto-observação da pesquisadora. Ou seja, incluí nas análises as sensações e influências que a convivência com os membros da ecovila provocou em minhas próprias práticas e atitudes (Bergson, 1974; Bosi, 2003; Oliveira, 2011).

\section{Criando um novo estilo de vida}

A ecovila estudada está localizada em uma Área de Preservação Ambiental a menos de duas horas de carro da cidade de São Paulo e a aproximadamente 30 minutos da cidade mais próxima. Fundada em 2005, tinha, na época da pesquisa, 98 membros adultos $-\mathrm{a}$ maior parte proveniente de classe média alta de São Paulo ou Campinas. No entanto, apenas oito moravam efetivamente na comunidade. Esses residentes tinham idades entre 46 e 70 anos, de profissões diversas: um médico, uma psicoterapeuta, uma juíza, um engenheiro aposentado, uma dona de casa, dois agrônomos e uma restauradora de livros. 
Muitos outros membros compraram um lote na ecovila, mas continuavam vivendo nas suas cidades de origem e participando da vida comunitária apenas aos finais de semana. Segundo alguns membros, os maiores entraves para que mais pessoas se mudem para lá são: a falta de oportunidades de trabalho no local e a ausência de uma escola de qualidade nas proximidades:

Eu acho que o grande nó daqui é isso: nós somos totalmente dependentes de São Paulo e de Campinas. Eu ganho a vida longe daqui. ... Não tem quem diga: "Eu moro aqui". ... Você consegue, buscando uma vida simples, plantando a sua comida, diminuir essa dependência. Então você vive com menos dinheiro, você diminui a sua dependência. Agora você imagine, por exemplo, se você viesse pra cá com a sua filhinha, onde é que ela vai estudar? Na cidade, não é? Onde é que você vai ganhar a vida pra mantê-la aqui? Não sei como é que se resolve esse nó.

Existe, portanto, uma grande dificuldade dos membros da ecovila em saírem da cidade, dos seus empregos, da escola de seus filhos, para morar na ecovila e criar um novo estilo de vida. Essa reorganização é dificultada, principalmente, por não se tratar de uma ecovila já estruturada, que oferece escola, trabalho etc., mas uma ecovila que está começando e na qual tudo precisa ainda ser construído.

Todo mês é realizada uma reunião comunitária, na qual todos ficam a par do que está acontecendo na comunidade, discutem seus planos e criam novas demandas para a ecovila. Nessas reuniões, os membros exercitam a autogestão e o diálogo, buscando convergir as diversas opiniões e visões de mundo em um projeto comum. Além disso, na ecovila, as decisões tomadas nas reuniões são executadas pelos próprios membros, por meio da criação de grupos de trabalho, nos quais os membros assumem tarefas voluntárias pela comunidade. Dessa forma, as decisões são tomadas pelo coletivo e executadas também de forma coletiva.

Uma das motivações que levaram as pessoas para a ecovila são os valores ambientais. Na ecovila, esses valores se traduzem em práticas cotidianas que visam à sustentabilidade. Seus membros procuram dar preferência a materiais reutilizáveis (coador de pano, fraldas de pano, coletores menstruais etc.); nas construções, os membros dão preferência para pedras e outros materiais retirados do próprio lugar (deixando, assim, de consumir combustíveis fósseis no transporte de materiais), além de reaproveitar portas, janelas e outros materiais usados. $\mathrm{O}$ uso do concreto é evitado, já que a sua fabricação consome grande quantidade de energia e libera grande quantidade de $\mathrm{CO} 2$, além de exigir matérias-primas extraídas por grandes mineradoras, que impactam o meio ambiente. Na ecovila, a preocupação com o consumo se estende, também, à economia de água e à qualidade dos alimentos. Todos os membros, mesmo os que não plantam, dão preferência a alimentos orgânicos e produzidos localmente.

A ecovila acaba por se tornar, também, local de experimentação em bioconstrução, como as técnicas de tijolos de adobe e superadobe. Todas as casas têm sistemas de captação de água das chuvas e painéis solares para o aquecimento das águas dos banheiros. A separação do lixo é obrigatória na ecovila. A maioria das casas tem as suas próprias composteiras, que fazem a decomposição controlada dos resíduos orgânicos, transformando-os em adubo. O esgoto das casas é tratado por biodigestores.

A crença é que aqui você tem uma casa que tem aquecimento solar, eu trato o meu esgoto, eu recebo água da chuva e lavo roupa, limpo a casa, rego as plantas, tomo banho. Não estou usando água limpa pra fazer isso. Cuido dos detergentes e das coisas que eu estou usando pra não poluir os lençóis freáticos pros filhos que estão nascendo. Essa é a crença.

Outra característica da ecovila é a busca de uma vida mais simples e menos consumista. Em seus momentos de lazer, os membros da ecovila dão preferência a atividades não intensivas no uso de recursos naturais: contemplação da natureza, almoços comunitários, meditações conjuntas, festas etc. Ao valorizar uma vida mais simples, eles colocam em segundo plano a busca incessante pelos produtos disponíveis no mercado, para que outras fontes de satisfação possam aflorar: a convivência, o lazer ativo e comunal, o relacionamento sensível com a natureza e a criação de novos projetos e ideias para a comunidade.

Isso não significa que excluam completamente a utilização de tecnologias. Quase todos os ecovilenses possuem carro, máquina de lavar, perfil no facebook, site na internet, além das tecnologias "verdes": aquecimento solar, captação de água da chuva, tratamento ecológico dos resíduos. O que muda é que existe uma conscientização no seu consumo e uma valorização dos trabalhos manuais e das atividades coletivas.

O que eu mais gosto da vida na ecovila é do contato com a natureza. Me faz bem. De uma vida mais simples. Não quer dizer mais pobre, não me falta nada. Mas de se liberar de algumas coisas da vida urbana neurótica, não é? Como o trânsito, como más notícias - eu não fico sabendo as más notícias porque eu não estou lá vendo os noticiários da televisão. De ver a coisa andando, às vezes até da lama, tudo são 
oportunidades, sabe? Assim, acalmar um pouco o ritmo de vida, acho que isso é o melhor. ... Depois que eu vim pra ecovila houve uma mudança assim de separar um pouco o joio do trigo; de ver o que é realmente importante do que você acha que é importante. Por exemplo: status, o carrão do ano, sei lá. Não que eu não goste de conforto, andar num carro bom, ou ir num hotel cinco estrelas. Mas você acaba vendo que isso ajuda, mas você pode viver sem isso e ser feliz do mesmo jeito.

E surgem muitas oportunidades, mas não quero voltar pra vida urbana. Porque não paga. Não tem preço o que eu recebo aqui. São coisas indiziveis. ... Tudo que eu quero, eu tenho. Meus desejos são muito simples. um bom instrumento, um carro suficiente, pra mim está bom. Um pouco pra mim, não me interessa muito. Então, meus desejos são muito simples. Eu me sinto muito bem com o que tenho sabe?

As pessoas na ecovila propõem, assim, uma redefinição das suas necessidades materiais. Não se trata, porém, somente de uma privação: não consumir as coisas, se sentir culpado ao comprar os produtos, ou se sentir forçado a uma vida simples. Trata-se, ao contrário, de uma reinvenção: abrir espaço para outras formas de satisfação e de busca da felicidade. Todos os membros entrevistados sentem que as suas vidas melhoraram com essa redefinição. Eles demonstram satisfação de estar vivendo de acordo com os seus valores e de compartilhá-los com um grupo.

Eu acho que estar aqui são as minhas convicções e crenças: respeito à natureza e gostar de vida introspectiva. ... Foi o gosto de viver com a natureza, viver com simplicidade. ... Eu acho que eu estou mais centrada. Estar aqui me deixa bem centrada, bem equilibrada. Eu tenho pessoas com afinidades e com os gostos que, enquanto eu estava só em Campinas, não tinha. Eu acho que estou conseguindo me tornar uma pessoa melhor.

E é um ambiente amigo. Um ambiente de pessoas que têm valores similares, apesar de tão diferentes que as pessoas sejam. Em qualquer momento, se eu chegar: "Por favor, estou precisando disso", a pessoa que me acha chata, ou que sei lá... Nunca deixei de ter do que eu precisei. Ser atendida, sabe? Nunca passei aperto.

A relação com o entorno. A relação com o vento, com a chuva, com a terra, com a lua, com o sol, com as estrelas. ... Mas a coisa mais interessante é reviver isso de novo, e ver o sol nascendo e ver a lua se pondo e ver o movimento do sol. Sentir, aqui você realmente percebe que a terra gira, entendeu? É outra conexão. Tudo colorido: amarelo, roxo, vermelho, lilás, verde, azul, é uma delícia! Eu acho que a humanidade tem que voltar pra terra, pro campo, sabe? Vai ter que acordar. Antes que ela vire um CD-ROM. Tem que saber que a vida está na terra, o alimento está na terra.

Os valores espirituais também são uma das motivações que levam as pessoas até a ecovila e a busca do autoconhecimento permeia diversas práticas do cotidiano dessas pessoas:

Eu acredito que essa busca que eu faço e que várias pessoas fazem com vários caminhos é o único caminho pra gente como humanidade ter algum futuro. Porque mesmo o caminho ecológico, que eu gosto, eu faço, se você não tiver uma busca de melhoria como ser humano, você não vai a lugar nenhum. Então eu acho que é o único caminho. E se você tem um caminho de autoconhecimento, de você querer se melhorar eticamente, querer se melhorar, como consequencia vem um respeito com a natureza, um respeito com outro ser humano, um respeito com os animais. E aí a coisa vai.

A busca dos membros da ecovila por uma nova forma de convivência exige uma mudança cultural, pois, na sociedade de consumo, os indivíduos são condicionados a fugir dos conflitos, a resolver seus problemas sozinhos, a serem autossuficientes e não dependerem de ninguém (Sennett, 2003). Tudo isso está inscrito em seus corpos, seus hábitos e automatismos. Trabalhar as diferenças, encarar o conflito, promover a solidariedade, tudo isso exige dos membros da ecovila uma mudança cultural, uma reeducação.

\begin{abstract}
Nunca morei. Não tinha nenhum conhecimento do que era morar em comunidade. Pra mim é tudo um aprendizado, tudo uma novidade. Eu vejo que as pessoas têm que exercitar uma tolerância maior, têm que ter mais abertura, têm que acreditar no outro. Então é um exercicio que eu estou fazendo e aprendendo, não é fácil também. ... Então você tem que saber conviver. Eu acho que é um aprendizado pra todo mundo. Aqui, particularmente, eu vejo que cada um, do tempo que eu conheci, teve um crescimento nessa questão ai do convívio. ... Numa comunidade ... você não fala assim: "eu estou fora" e fecha a sua porta e fecha seu espaço. Se você fizer isso, já está claro que você é uma pessoa que já nem devia estar ali. É uma pessoa que tem dificuldade de se relacionar, de aceitar o outro, de se aceitar, de se fazer aceitar. Então é difícil, essa pessoa vai sofrer.
\end{abstract}

Nesse processo de mudança, não deixam de apresentar as suas contradições. Por exemplo, em um almoço comunitário, uma mulher estava presente com o seu bebê de poucos meses. Quando a mesa estava posta, todos correram para fazer seus pratos, sem notar que ela ficou de lado, com o bebê no colo. No relacionamento com os funcionários (muitos membros contratam jardineiros e faxineiras), por mais que o 
grupo esteja aberto a aprender com os habitantes locais, especialmente quando se trata de plantio, pesca etc., observei, em diversas situações, relações hierárquicas. Ao convidar a faxineira para almoçar, por exemplo, um dos membros fez um prato para a moça e colocou-o sobre o balcão da cozinha, mesmo que estivéssemos comendo na mesa da sala. Em um dia de chuva, um jardineiro trabalhava no jardim de uma casa e não foi convidado a entrar, nem mesmo na hora do café.

Os membros da ecovila estudada, portanto, embora busquem valorizar uma vida simples e relações solidárias, não conseguiram abrir mão da necessidade de delegar os trabalhos de limpeza e conservação para funcionários. Fica visível a persistência do habitus criado pela socialização dos seus membros em uma sociedade de classes e a forma como esse habitus reproduz as desigualdades sociais e culturais da sociedade de consumo.

Outra dificuldade encontrada no processo de mudança cultural é que, mesmo compartilhando de valores comunitários, ecológicos e espirituais, existem na ecovila diversas opiniões e visões de mundo contraditórias que precisam ser integradas para a construção de um projeto coletivo.

Um exemplo? O Centro Comunitário. Então tem pessoas que acham que pra você construir qualquer coisa você tem que planejar. Se você vai fazer um Centro Comunitário, você tem que pagar um arquiteto muito bom e que vai fazer uma coisa certa, perfeita. Tem outros que acham que isso é o fim do mundo: se nós estamos aqui, numa ecovila, a gente tem que fazer com as nossas mãos, com nossos saberes $e$, se sair mais ou menos, não tem importância porque fomos nós que fizemos. Então isso dá conflito. Então são formas bem antagônicas de ter um único objetivo que é o tal do Centro Comunitário.... Então existem várias formas de ver o mundo e existem várias personalidades, então existem conflitos de como se vai fazer acontecer.

As divergências são um ponto de complicação que a gente precisa trabalhar sempre, porque existem. As pessoas têm as suas histórias de vida, suas convicções $e$ às vezes são situações trabalhosas pra gente conversar, discutir, nesse modelo democrático que a gente tem. ... Algumas pessoas vieram pra cá por conta do cuidado com a natureza, outros vieram por causa do social e não conhecem nada de natureza. Tem pessoas que vieram e não sabem nem pisar na terra direito, mas têm a boa vontade de querer viver uma vida alternativa ao sistema socioeconomico $e$ ambiental que tem. E ai essas diferenças podem gerar formas de ver o mundo diversas: com mais conforto, com menos conforto, com que tipo de animal tem, com que tipo de animal não tem, o que significa ter as coisas ou não ter. E, eventualmente, tem umas discordâncias em relação a ponto de vista ou aspectos que podem criar um stress temporário, mas que nós aprendemos a lidar com isso, conversando.

Cada membro também apresenta um ritmo de participação diferente. Enquanto alguns membros têm pressa na concretização dos projetos, pois já estão morando na ecovila ou gostariam de se mudar para lá em breve, outros ainda não podem investir tempo e dinheiro, pois estão focados em seus projetos na cidade. Dessa forma, os membros mais atuantes acabam tendo de abrir mão de algumas expectativas para esperar o tempo do grupo. Além disso, muitos membros têm mais de 50 anos e viveram toda a sua vida em metrópoles. Muitos apresentam, portanto, mais dificuldades nessa transição para um novo modo de vida.

Eu sonho, sim, que as pessoas fossem mais presentes, que fossem mais terra. Mas, como eu disse, é o meu desejo. Mas as pessoas têm o seu tempo de voltar pra terra, sabe? Por exemplo, eu vejo muitas pessoas que evoluiram aqui dentro. Gente que tinha medo de pisar no chão, porque "tem bactéria" (não sei por que vem pra cá!), mas hoje em dia já anda descalço. Então, já houve uma evolução. ... Então eu fico contente com essas pequenas evoluções. É como eu sempre falo: o caminhante não tem que chegar nalgum lugar, ele tem que caminhar. E o caminhar é que faz o prazer, a alegria da coisa, não é?

Eu acho que entre o que a gente idealiza, le, a receita, e o que a gente encontra, seja aqui ou em qualquer comunidade, tem um processo de adaptação, de acomodação. Esse processo pode ser muito violento ou frustrante, porque você vê que é uma coisa na teoria e na prática é outra, ou pode ser uma oportunidade muito gratificante de você se entregar e deixá-lo acontecer. No começo a maioria vem com aquela primeira intenção de querer consertar pela ideia que ele traz na cabeça. Mas quando ele percebe que é o que tem, e ele entra e permite que vire uma construção coletiva, que esse é o objetivo, aí a coisa fica mais suave, e mais legal.

Outros exemplos dessa dificuldade de transição foram observados durante o campo. Um dos membros, por exemplo, para ir até a casa de um vizinho, saiu de casa e entrou imediatamente no carro. Só depois é que percebeu que poderia ter ido a pé. Por mais que os membros da ecovila procurem evitar o consumo de combustíveis fósseis, ainda dependem do uso frequente de carros.

Existe, portanto, um processo de construção que se dá na estrutura física e organizacional da comunidade: construção do centro comunitário, construção das casas, consolidação dos acordos e tomadas de decisão coletivas. Mas existe ali, também, 
um processo de construção de novos hábitos e formas de ação. Cada membro passa por um processo em que precisa se distanciar do estilo de vida urbano e individualista e aprender a estar em um projeto rural e coletivo: abrir mão de suas preferências para aceitar a decisão do grupo, trabalhar os conflitos interpessoais, abrir mão de certos confortos e comodidades, doar tempo e energia para a comunidade. Tudo isso exige um trabalho de mudança pessoal e coletiva, uma mudança cultural.

\begin{abstract}
Olha, no começo você fica assim meio peixe fora d'água. Porque eu não tenho cultura de morar em casa, sempre morei em apartamento. E eu não entendo nada de terra, de plantio, essas coisas. Então eu tive que "mudar o chip", vamos dizer assim. O silêncio, $o$ vento, os ritmos, acordar mais cedo, dormir mais cedo. Até você começar a entender essas dinâmicas da natureza, você tem que se acostumar. ... Mas é uma outra dinâmica. E não tem internet, não tem televisão. O que você vai fazer? Você vai curtir a sua casa (a sua casa eu digo o espaço interno e externo) e vai curtir o entorno e as pessoas, é isso que a gente faz. ... Então a gente procura vivenciar muito mais as relações do que a gente teria em São Paulo, por exemplo, que eu moro em prédio e muitas vezes eu não conheço o vizinho de porta.
\end{abstract}

Em um contexto da sociedade de consumo, na qual os indivíduos têm a sua experiência de vida marcada pelo anestesiamento do corpo, pelo individualismo e consumismo (Sennett, 2003), os membros da ecovila estudada, apesar de suas limitações e dificuldades, se mostram como pessoas dispostas a transformar as suas práticas cotidianas. Trata-se de pessoas com boas condições financeiras. Poderiam, facilmente, usufruir de todos os confortos do estilo de vida consumista. Poderiam passar os finais de semana em clubes ou condomínios fechados, com toda a infraestrutura pronta, onde não precisariam interagir com os vizinhos, nem tomar decisões de forma coletiva. No entanto, essas pessoas optaram por um estilo de vida diferenciado, em busca de uma nova forma de convivência. São pessoas que se propuseram a sair de sua zona de conforto: levando uma vida mais simples, interagindo mais com os vizinhos, participando de atividades comunitárias, diminuindo o consumo de bens materiais e midiáticos, discutindo e tomando decisões de forma coletiva, trabalhando pela comunidade etc.

Eu acho que só o aprendizado do lidar com o outro, não é? Do respeito. Isso foi um aprendizado grande. Porque uma coisa é você fazer uma coisa pra você, você atender as suas necessidades, as suas vontades. Outra coisa é você fazer algo que precisa agradar um entorno, que você precisa ter uma ética, que você precisa ter um cuidado com o outro. Que você não pode falar qualquer coisa pro outro. ... Então isso mudou muito, porque, de repente, você vê que você tem que respeitar o outro e não dá pra você fazer as coisas sozinha.

Existe, portanto, na ecovila, um processo de mudança cultural, apesar dos desafios e contradições que seus membros apresentam. Essa mudança fica mais evidente nas práticas ecológicas que desenvolvem, na forma como consomem, na sua relação com a natureza e nas relações interpessoais entre os membros da ecovila.

A convivência com os membros da ecovila me levou a adotar, em meu cotidiano, diversas práticas sustentáveis. No entanto, quando a pesquisa de campo foi concluída e deixei de visitar a ecovila, muitas práticas que eu havia adotado deixaram de ser praticadas. Isso possivelmente ocorreu porque as novas práticas ainda não haviam sido repetidas a ponto de se incorporarem e se tornarem hábitos. Sem a motivação gerada pela convivência com o grupo da ecovila, articulando de forma explícita essas tentativas de mudança, a rotina e os hábitos normatizados pela sociedade em que vivo voltaram a exercer a sua força.

\section{Discussão e conclusões}

A mudança de estilo de vida proposta pela ecovila exige uma mudança cultural. Neste caso, não se trata tanto de uma mudança simbólica ou valorativa - pois os seus membros já tinham esses valores e essa forma de pensar antes de irem para a ecovila, sendo esse o motivo que os levou até ali. A infraestrutura e as tecnologias também não são impedimentos à mudança das práticas, neste caso, pois na ecovila existe a possibilidade de construção de casas e estruturas adaptadas às práticas sustentáveis que querem desenvolver. O maior desafio que essas pessoas encontram é o de vivenciar esses novos valores em sua vida cotidiana. Essa mudança exige que os indivíduos transformem hábitos e automatismos criados pela repetição de formas de ação da sociedade urbana e de consumo.

Por mais que haja na ecovila estudada uma intenção declarada de modificar comportamentos cotidianos, o grupo se depara com inúmeras dificuldades e contradições: a dificuldade em romper com o trabalho e outras instituições estabelecidas; abandonar hábitos internalizados por uma cultura hierárquica; adaptar-se à vida no campo; aprender a trabalhar e tomar decisões de forma coletiva etc. Essas contradições acontecem porque a mudança de vida à qual se propõem não é uma mudança meramente 
conceitual e valorativa, mas também corporal. Modificar as estratégias de ação cotidianas exige, mais do que uma decisão racional, a transformação de hábitos incorporados e não conscientes que tendem a persistir com o tempo. Tomar consciência desses desafios, discuti-los e problematizá-los em conjunto deve ser o primeiro passo para a sua superação.

A transformação das práticas cotidianas demanda tempo e um trabalho de percepção consciente até que as novas práticas sejam incorporadas nos corpos-mentes dos praticantes, criando novas memórias de práticas mais sustentáveis. Somente com o tempo e a repetição essas novas práticas tornam-se automáticas e deixam de exigir uma reflexão consciente para serem executadas. A presença de um grupo articulando essas tentativas de mudança ajuda a trazer essa mudança para a consciência.

Com base nessas reflexões, podemos sugerir que, se os membros da ecovila querem efetuar uma mudança cultural mais profunda, inclusive estabelecendo relações mais solidárias com os funcionários, é preciso que se tornem conscientes dessas contradições e formulem de maneira mais clara qual o tipo de relação que eles querem estabelecer com habitantes locais. Quanto mais explícitas e articuladas forem essas tentativas de mudança, e quanto mais compartilhadas pelo grupo, maiores são as chances de sua efetiva incorporação no cotidiano dos indivíduos. Formas de ação que não são conscientemente examinadas tendem a seguir hábitos familiares e internalizados pelas experiências passadas.

Essas considerações indicam que a maior dificuldade encontrada na adoção de práticas mais sustentáveis não é somente a falta de preocupação ou valores pró-ambientais, mas a rotinização de um estilo de vida insustentável. Essa rotinização está ligada não só às infraestruturas e materiais disponíveis no cotidiano das pessoas, mas, também, às normas culturais da sociedade de consumo, que tendem a normatizar práticas hierárquicas e intensivas em recursos. A criação de novos hábitos é um processo que demanda tempo e um trabalho de percepção consciente. Precisa, portanto, estar embasado em um desejo explícito e declarado de mudança.

A ecovila, como uma comunidade que compartilha desse desejo, se torna um ambiente que facilita essa mudança. Para Lewin (1983), a presença de um grupo solidário facilita o processo de mudança cultural, pois ao

ancorar sua própria conduta em algo grande, substancial e supraindividual, como a cultura de um grupo, é que o indivíduo pode estabilizar suas novas crenças o suficiente para mantê-las imunes das flutuações diárias de estados de ânimo e de influências a que ele está sujeito como indivíduo. (Lewin, 1983, p. 75)

O grupo, ao articular e compartilhar essas tentativas de mudança, favorece a reflexão sobre elas e a sua percepção consciente. Isso foi percebido na minha própria experiência, quando me afastei da ecovila e acabei por voltar às práticas habituais.

Este estudo restringiu-se a estudar um reduzido número de ativistas que procuram realizar uma mudança cultural. Os resultados obtidos neste estudo de caso não podem ser generalizados para a sociedade mais ampla, nem mesmo para o movimento das ecovilas como um todo. No entanto, apesar de suas limitações, este estudo traz uma contribuição relevante para a discussão sobre mudança cultural e sustentabilidade: a importância do fator corporal. Pesquisas quantitativas sobre comportamento ambiental abundam. No entanto, a discussão sobre o tema poderia se beneficiar de mais pesquisas qualitativas interdisciplinares. Observações e entrevistas em profundidade, em outros contextos de mudança cultural na direção da sustentabilidade, e com diferentes subgrupos, podem oferecer novos insights sobre a relação entre valores e percepções, de um lado, e ação prática, do outro.

\section{Nota}

${ }^{1}$ As citações em língua inglesa foram livremente traduzidas pela autora.

\section{Referências}

Abrahamse, W. \& De Groot, J. I. M. (2013). The psychology of behaviour change: an overview of theoretical and practical contributions. In S. Fudge, M. Peters, S. M. Hoffman, \& W. Wehrmeyer (Eds.), The Global Challenge of Encouraging Sustainable Living: Oportunities, Barriers, Policy and Practice (pp. 3-17). Cheltenham: Edward Elgar Publishing Limited.

Alibeli, M. A. \& White, N. R. (2011). The Structure of Environmental Concern. International Journal of Business and Social Science, 2(4), 1-8.

Bergson, H. (1974). Introdução à metafísica. In Coleção: Os pensadores, v. XXXVIII (pp. 17-45). São Paulo: Abril Cultural.

Bergson, H. (2010). Matéria e memória: ensaio sobre a relação do corpo com o espirito. São Paulo: WMF Martins Fontes.

Best, H. \& Mayerl, J. (2013). Values, Beliefs, Attitudes: An Empirical Study on the Structure of Environmental Concern and Recycling Participation. Social Science Quarterly, 94(3), 691-714.

Bosi, E. (2003). O tempo vivo da memória: ensaios de psicologia social. São Paulo: Ateliê Editorial.

Bourdieu, P. (1995). Outline of a theory of practice. Cambridge: Cambridge University Press. Recuperado de https:// monoskop.org/images/7/71/Pierre_Bourdieu_Outline 
of a Theory of Practice Cambridge Studies in Social and_Cultural_Anthropology_1977.pdf

Bourdieu, P. (2009). O senso prático. Petrópolis, RJ: Vozes.

Bourdieu, P. (2012). O poder simbólico. Rio de Janeiro: Bertrand Brasil.

Boyer, R. (2016). Achieving one-planet living through transitions in social practice: a case study of Dancing Rabbit Ecovillage. Sustainability: Science, Practice \& Policy, 12(1), 1-6.

Capello, G. (2013). Meio ambiente e ecovilas. São Paulo: Senac.

De Groot, J. I. M. \& Steg, L. (2010). Relationships between value orientations, self-determined motivational types and pro-environmental behavioural intentions. Journal of Environmental Psychology, 30(4), 368-378.

Dunlap, R. E. (1994). International Attitudes Towards Environment and Development. In Beresen \& Parmann (Eds.), Green Globe Yearbook of International Co-operation on Environment and Development 1994 (pp. 115-126). Oxford: Oxford University Press.

Ergas, C. (2010). A Model of Sustainable Living: Collective Identity in an Urban Ecovillage. Organization \& Environment, 23(1), 32-54.

Ester, P., Vinken, H., \& Simões, S. (2004). Cultural Change and Environmentalism: a cross-cultural national approach of mass publics and decision makers. Ambiente \& Sociedade, $\operatorname{VII}(2), 45-66$.

Feinberg, M. \& Willer, R. (2013). The moral roots of environmental attitudes. Psychological Science, 24(1), 56-62.

Feldenkrais, M. (1977). Consciência pelo movimento. Sâo Paulo: Summus.

Feldenkrais, M. (1988). Vida e movimento. São Paulo: Summus.

Fudge, S., Peters, M., Hoffman, S. M., \& Wehrmeyer, W. (2013). Introduction. In The Global Challenge of Encouraging Sustainable Living: opportunities, barriers, policy and practice (pp. xix-xxvi). Cheltenham: Edward Elgar Publishing Limited.

Giddens, A. (2007). The Constitution of Society: Outline of the Theory of Structuration. Cambridge: Polity Press.

Gonçalves, B. V. \& Gomes, L. J. (2014). Percepção ambiental de produtores rurais na recuperação florestal da sub-bacia hidrográfica do rio Poxim - Sergipe. Desenvolvimento E Meio Ambiente, 29, 127-138.

Harder, M. K., Velasco, I., Burford, G., Podger, D., Janousková, S., Piggot, G., \& Hoover, E. (2014). Reconceptualizing "effectiveness" in environmental projects: Can we measure values-related achievements? Journal of Environmental Management, 139, 120-134.

Kaiser, F., Wolfing, S., \& Fuhrer, U. (1999). Environmental attitude and ecological behaviour. Journal of Environmental Psychology, 19(1), 1-19.

Lewin, K. (1983). Problemas de dinâmica de grupos. São Paulo: Cultrix.

Lizardo, O. (2009). Is a "Special Psychology" of Practice Possible?: From Values and Attitudes to Embodied Dispositions. Theory \& Psychology, 19(6), 713-727.

Maller, C. J. \& Strengers, Y. (2015). Resurrecting sustainable practices: using memories of the past to intervene in the future. In Y. Strengers \& C. J. Maller (Eds.), Social practices, intervention and sustainability: beyond behaviour change (pp. 145-160). Oxon: Routledge.

Oliveira, P. S. (2011). O respeito às diferenças e a alternância de condição entre sujeito e objeto do conhecimento: questões de proximidade e distanciamento. In M. I. Leme \& P. de S. Oliveira (Eds.), Proximidade e distanciamento: superando dicotomias (pp. 11-22). São Paulo: Casa do Psicólogo.

Peterlin, M., Kross, B. C., \& Kontic, B. (2008). A method for the assessment of changes in environmental perception during an EIA process. Environmental Impact Assessment Review, 28(8), 533-545.

Raskin, P., Banuri, T., Gallopín, G., Gutman, P., Hammond, A., Kates, R., \& Swart, R. (2002). Great Transition: the promise and lure of the times ahead. Boston: Stockholm Environmental Institute.

Raskin, P. D., Electris, C., \& Rosen, R. A. (2010). The Century Ahead: Searching for Sustainability. Sustainability, 2(8), 2626-2651.

Ratter, B. M. W., Philipp, K. H. I., \& Von Storch, H. (2012). Between hype and decline: recent trends in public perception of climate change. Environmental Science \& Policy, 18, 3-8.

Reckwitz, A. (2002). Toward a theory of social practices: A development in culturalist theorizing. European Journal of Social Theory, 5(2), 243-263.

Rodríguez-Barreiro, L. M., Fernández-Manzanal, R., Serra, L. M., Carrasquer, J., Murillo, M. B., Morales, M. J., Calvo, J., \& Del Valle, J. (2013). Approach to a causal model between attitudes and environmental behaviour. A graduate case study. Journal of Cleaner Production, 48, 116-125.

Sampieri, R. H., Collado, C. F., \& Lucio, M. P. B. (2013). Metodologia de pesquisa. Porto Alegre: Penso.

Sennett, R. (2003). Carne e pedra: o corpo e a cidade na civilização ocidental. Rio de Janeiro: Record.

Shove, E., Pantzar, M., \& Watson, M. (2012). The Dynamics of Social Practice: Everyday Life and How it Changes. London: SAGE.

Shove, E. \& Walker, G. (2010). Governing transitions in the sustainability of everyday life. Research Policy, 39(4), 471476.

Shove, E., Watson, M., \& Spurling, N. (2015). Conceptualizing connections: Energy demand, infrastructures and social practices. European Journal of Social Theory, 18(3), 274287.

Spaargaren, G. (2011). Theories of practices: Agency, technology, and culture. Exploring the relevance of practice theories for the governance of sustainable consumption practices in the new world-order. Global Environmental Change, 21(3), 813-822.

Steffen, W., Sanderson, A., Tyson, P. D., Jager, J., Matson, P. A., Moore III, B., Oldfield, F. et al. (2005). Global Change and the Earth System: a planet under pressure. Würzburg: Springer.

Swidler, A. (1986). Culture in Action : Symbols and Strategies. American Sociological Review, 51(2), 273-286.

Tanner, C. (1999). Constraints on Environmental Behaviour. Journal of Environmental Psychology, 19(2), 145-157.

Thomas, C., \& Sharp, V. (2013). Understanding the normalisation of recycling behaviour and its implications for other pro-environmental behaviours: A review of social norms and recycling. Resources, Conservation and Recycling, 79, 11-20.

Submissão em: 20/05/2016

Revisão em: 10/10/2017

Aceite em: 11/02/2018 


\section{Agência de fomento}

Coordenação de Aperfeiçoamento de Pessoal de Nível Superior - CAPES (bolsa de doutorado) .
Rebeca Roysen é doutora em Desenvolvimento Sustentável (UnB) e mestra em Psicologia Social (USP). Endereço para correspondência: Caixa Postal 79 - Alto Paraíso de Goiás/GO, Brasil. CEP 73770-000. E-mail: rebecaroysen@gmail.com 